\title{
ADVANCED DAMAGE STABILITY ASSESSMENT FOR SURFACE COMBATANTS
}

\author{
Evangelos Boulougouris ${ }^{\mathrm{a}}$, Stuart Winnie ${ }^{\mathrm{a}}$, Apostolos Papanikolaou ${ }^{\mathrm{b}}$ \\ a) Naval Architecture, Ocean and Marine Engineering, University of Strathclyde, Glasgow G4 OLZ, Scotland \\ E-mail: evangelos.boulougouris@strath.ac.uk \\ b) School of Naval Architecture and Marine Engineering, National Technical University of Athens, Athens, Greece \\ E-mail:papa@deslab.ntua.gr \\ Corresponding Author: Evangelos Boulougouris
}

\begin{abstract}
One of the major contributors to the survivability of a surface combatant is her reduced vulnerability to weapon effects and as such the ship's damage stability characteristics determine a ship's ability to resist the consequences of possible flooding, namely to not capsize and/or sink. There are serious concerns about the limitations of the current semiempirical deterministic criteria in which a combatant's damage stability is assessed upon. This paper details a comparison between the current approach and a newly presented probabilistic approach with the aim of determining which will result in a more accurate way of estimating the level of survivability of a particular design. A study is also presented in which the maximum damage length used in the naval ship assessment is increased to merchant ship standards of $0.24 \mathrm{~L}_{\mathrm{bp}}$.
\end{abstract}

\section{KEYWORDS}

Naval ships, damage stability, risk, probabilistic assessment, survivability

\section{INTRODUCTION}

Surface warships differ from other categories of ships in that they are designed to operate in a man-made hostile environment. In addition to being able to withstand damage from collision and grounding, a surface combatant must be able to avoid and withstand the effects of modern anti-ship weapons. As warships are designed and built to support high-end combat operations, survivability and the ability to 'fight hurt' is a vital design objective.

One of the main contributors to a surface combatant's survivability is her invulnerability to weapon effects and as such the damage stability and floatation characteristics of the vessel determine its vulnerability. Therefore, it is critical for the designer to minimise the vulnerability of the vessel from the early design stages in order to maximise its survivability. This can be achieved through the use of optimal subdivision, adequate reserved buoyancy and by considering a large number of damage scenarios and combinations of operational and environmental conditions.

For the past half of century the majority of warship stability criteria was based on a set of empirically defined stability criteria proposed by Sarchin and Goldberg (1960) based largely on WWII battle damage experience. The criteria used by major navies such as the U.S Navy (USN) and Royal Navy (RN) have been reviewed over the years however, there have been no significant changes yet. Although the criteria have served their purpose for many years, they now appear to be outdated, given the advances in our capability to simulate the behaviour of a ship after damage (Harmsen, 2000; Mc Taggart, 2000), and there are serious concerns about 
their limitations and applicability to modern naval ship designs. Some of the shortfalls of the criteria incluide (Surko, 1994);

- Capability of modern warships to survive damage from current threats, in demanding environmental conditions, is not known

- Modern hull forms and construction techniques differ greatly from the ships used to determine the criteria

- Assumption of moderate wind and sea conditions at the time of damage

This suggests that even though a vessel may comply with the standards outlined, the designer and operator may not have a clear understanding of the survivability performance and operational limits of their vessel.

In view of these shortcomings a number of naval organisations established the Co-operative Research Navies (CRNav) Dynamic Stability group back in 1989 with the aim to provide better understanding to the physical phenomena and characteristics of dynamic stability (Perrault, 2010). This led to the formation in 1999 of the Naval Stability Standards Working Group (NSSWG) tasked to develop " a shared view on the future of naval stability assessment and develop a Naval Stability Standards Guidelines document which can be utilized by the participating navies at their discretion" (Perrault, 2010).

In contrast to the slow progress of naval standards, the International Maritime Organisation (IMO) have made significant advances in terms of upgrading safety standards of merchant vessels. The acceptance of the new harmonized probabilistic damage stability framework of SOLAS 2009 for the damage stability assessment of passenger and dry cargo vessels shows that the maritime industry and regulatory bodies are convinced that this is the right way forward. Boulougouris and Papanikolaou (2004) previously presented a methodology for the probabilistic damaged stability assessment of naval combatants and its application to their design optimisation. The methodology allows the risk that the vessel will be lost, as a result of damage, to be quantified. Thus, minimal risk can become a design optimisation objective and the surface naval ship can be optimised for minimum risk while still being efficient and economical.

This paper details a comparative study of the currently used semi-empirical deterministic approach and the proposed quasi-static probabilistic approach to assessing the damage stability of a surface combatant. Each approach is applied to a generic frigate and the merits and shortcomings of each method along with the results are presented. In addition, a study was carried out on a frigate which meets the current deterministic criteria in order to observe the effects of increasing the survivable damage length.

\section{SURVIVABILITY}

The survivability of a naval combatant can be defined as "the capability of a (naval) ship and its shipboard systems to avoid and withstand a weapons effects environment without sustaining impairment of their ability to accomplish designated missions" (Said, 1995). Survivability consists of two main aspects;

- Susceptibility - Inability of the ship to avoid being damaged in operation and is also referred to as the probability of being hit $\left(\mathrm{P}_{\mathrm{H}}\right)$

- Vulnerability - Inability of the ship to withstand the effects of a threat weapon and is also referred to as the probability of serious damage or loss when hit $\left(\mathrm{P}_{\mathrm{K} / \mathrm{H}}\right)$ 
Survivability is the opposite of killability which is the probability that the ship will be lost due to enemy action. Killability can be described mathematically as the product of susceptibility and vulnerability. A ship kill can be expressed in many different ways, in this case the definition given by Ball \& Calvano (1994) is referred to;

- System Kill - damage of one or more compartments which leads to the failure of a ship system.

- Mission Area Kill - damage which leads to the loss of a mission critical area such as Anti -Air Warfare (AAW)

- Mobility Kill - damage which leads to the ship being immobilised through the loss of propulsion or steering.

- Total Ship Kill - damage which leads to the loss of the ship through insufficient buoyancy, loss of transverse stability or abandonment due to fire.

The mathematical relationship between survivability $\left(\mathrm{P}_{\mathrm{s}}\right)$, susceptibility and vulnerability is as follows (Ball and Calvano, 1994):

$$
P_{S}=1-\left(P_{H} \times P_{K / H}\right)
$$

The relationship infers that both susceptibility and vulnerability are of equal importance to the survivability of the vessel. Some naval design philosophies have included to 'design for peace' as the probability of being damaged in operation is very low. They will therefore accept that in the event of a hit that the vessel will be out of action or have limited participation in the operation. Thus their focus has been to minimise the susceptibility of the vessel. Most of the scenario simulations ran would assume a single hit has a kill probability equal to one for smaller vessels and two hits would be assumed sufficient to sink a larger vessel. Although modern surface ships are powerful military assets on the open ocean, they lose their advantage near shore. Even the stealthiest vessel is susceptible to asymmetrical threats. Thus, by treating the vulnerability as a property with a deterministic outcome, pass or fail, it is not possible to truly quantify the survivability of the vessel.

\section{DETERMINISTIC ASSESSMENT}

Currently both the USN and RN use deterministic criteria to assess the stability of naval ships after damage. The stability standards previously used by the UK MOD, NES 109, was recently reissued in DEFSTAN 02-900 part 1: Ship safety \& Environmental Protection (UK MOD, 2013). However, the criteria used in the assessment of stability and reserve buoyancy after damage remain unchanged. Table 1 shows the semi-empirical damage stability criteria currently used by the USN and RN for surface combatants. Both use a damage length of $15 \%$ $\mathrm{L}_{\mathrm{wl}}$ for larger vessels however the UK also implements a minimum damage length of $21 \mathrm{~m}$. Although the survivability requirements between naval ships and merchant vessels differ significantly it is of interest to note that the current IMO probabilistic damage approach considers damage extents up to $24 \%$.

Although both criteria are very similar the UK criteria are slightly more demanding, namely the use of a 15 degree roll back angle requires that UK warships have a greater righting energy to achieve the same reserve dynamic stability criteria. In addition, the use of a minimum length of damage shows progress towards a threat based standard for damage length. 
Table 1 - Current UK and US damage stability criteria for surface combatants

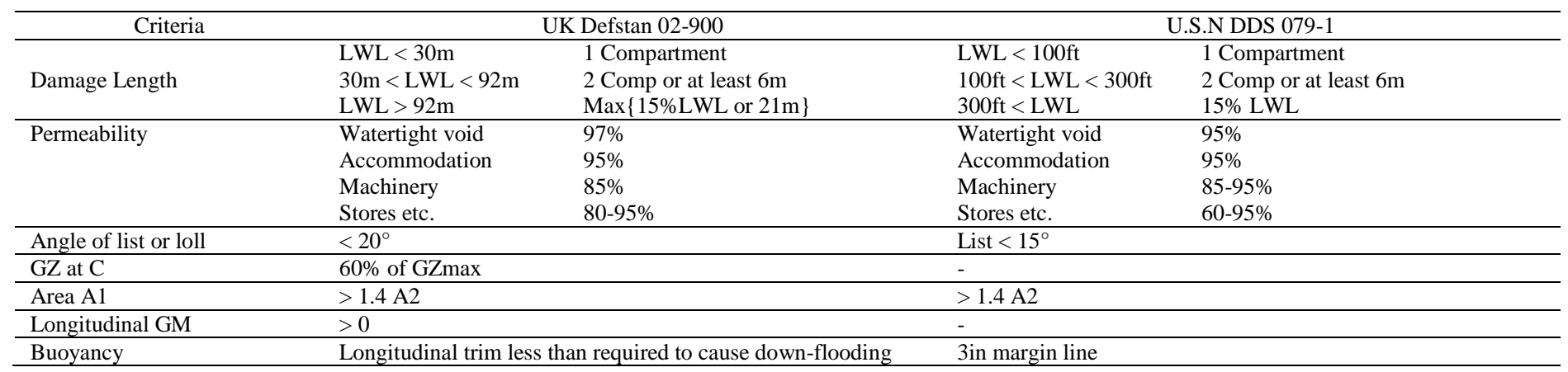

\section{PROBABILISTIC ASSESSMENT}

Boulougouris and Papanikolaou $(2013,2004)$ previously presented a methodology for the probabilistic damaged stability assessment and its application to design optimisation. It is based on the fundamentals of the probabilistic damage stability concept for passenger vessels introduced by Wendel (1960) and its derivatives (IMO Resolution A.265; IMO MSC.19 (58); IMO MSC.216 (82)) which are used to assess the ships level of safety after damage. The probabilistic approach uses the probability of survival after damage as a measure of the ships safety when damaged. The approach considers the following probabilities of events as being relevant to the ships damage stability;

- The probability that a compartment or group of compartments i may be flooded (damaged), $\mathrm{p}_{\mathrm{i}}$.

- The probability that the ship will survive after flooding of the compartment or group of compartments $\mathrm{i}$ under consideration, $\mathrm{s}_{\mathrm{i}}$.

The total probability of survival is expressed by the attained subdivision index, A, and is the given by the sum of the product of $\mathrm{p}_{\mathrm{i}}$ and $\mathrm{s}_{\mathrm{i}}$ for each compartment and compartment group, $\mathrm{i}$ along the ships length.

$$
A=\sum_{i} p_{i} \cdot s_{i}
$$

In order for a vessel to comply with the IMO probabilistic method for passenger and dry cargo ships (IMO MSC.216 (82)) the attained subdivision index must be greater than or equal to the required index. This ensures that the vessel is designed with an acceptable level of risk. The effect of sea state on survivability is implicitly accounted for in the IMO probabilistic damage stability method, namely the formulation of the $\mathrm{s}_{\mathrm{i}}$ factor is derived from an empirical relationship between $\mathrm{GZ}_{\max }$, range and critical sea state ( $\mathrm{HS}_{\text {crit }}$ ) for a sample of ships. In this method the critical sea state is defined as the limiting sea state at which the ship will have a $50 \%$ chance of survival (or not), if exposed to the action of waves for 30 minutes (Jasionowski and Vassalos, 2011).

The required subdivision index $\mathrm{R}$ for dry cargo and passenger ships is a function of ship's size (in terms of subdivision length), the number of people onboard and life boat capacity in case of passenger ships. This required index (R) is consistent with the mean value of the 
attained index (A) from a sample of ships of relevant type, size and passenger capacity (as applicable), which dispose in principle a similar level of damage stability risk and acceptable survival characteristics. Likewise, for warships, an acceptable level of risk could be specified by either the owner (navy) or approval authority (NATO/ classification society) considering the desired survival properties of a surface combatant as expressed by the average value of calculated attained indices of a satisfactory sample of relevant ships.

For naval vessels in general there is a probability that the ship will be targeted and engaged which may be leading to the flooding of one or more compartments. The damage can occur at any point along the ship's hull and can vary extensively in magnitude. The extent of damage is dependent on both the characteristics of the target (ship) and the threat (weapon). As the survivability of the vessel is determined by the vulnerability and susceptibility, the probability distribution for damage of a naval ship relates both characteristics.

The probability of survival of a particular function of the ship can be extracted from the total attained index, which represent the ships floatability and stability after damage. If $j^{*}=\{j 1, j 2$, $\mathrm{j} 3, . ., \mathrm{jn}\}$ is the set of compartments that host all systems of the particular function $\mathrm{F}$, then the damage of any set $\mathrm{j}$ that includes $\mathrm{j}^{*}$ will impair the ship from function $\mathrm{F}$. Therefore, the probability of survival of the particular function is calculated using the following formula:

$$
S_{f}=\sum_{i} p_{i} \cdot s_{i}-\sum_{j} p_{j} \cdot s_{j}
$$

where $\mathrm{j}$ are all damage cases, which include the compartment set $\mathrm{j}^{*}$.

\subsection{Determining $p_{i}$}

During the initial stages of a naval ship's design, when there is a lack of refined information for the threat's signature distribution along the ship it can be assumed that the probability of weapon impact along the hull follows a basic mathematical distribution, such as the piecewise linear distribution. Boulougouris and Papanikolaou (2004) propose that for air-tosurface missile (ASM) threats, a piecewise linear distribution with maximum probability amidships can be used. As both the ships radar profile and heat emissions due to machinery and exhaust are highest at amidships this is the most likely aim point of the weapon. For contact mines a linear distribution can be assumed (Harmsen and Krikke, 2000). Thus the impact point probability density function in the missile's case with a piecewise linear distribution is;

$$
\operatorname{imp}(x)=\left\{\begin{array}{cc}
4 x & x \leq 0.5 \\
-4 x+4 & x \geq 0.5
\end{array}\right.
$$

The damage length probability density distribution is based on the concept of the Damage Function used in the theory of Defence Analysis (Przemieniecki, 1994). The well-known lognormal distribution considered the most appropriate for this case. Thus, the damage length probability density distribution is given by the following formula;

$$
\operatorname{Dam}(y)=\frac{1}{\sqrt{2 \cdot \pi} \cdot \beta \cdot y} \cdot \exp \left[-\frac{\ln ^{2}(y-\alpha)}{2 \beta^{2}}\right]
$$

Where; 


$$
\alpha=\sqrt{L_{S S} L_{S K}}, \beta=\frac{1}{2 \sqrt{2} z_{s S}} \ln \left(\frac{L_{S S}}{L_{S K}}\right)
$$

Where $\mathrm{L}_{S K}$ is the sure kill length which means that $\mathrm{d}\left(\mathrm{L}_{S K}\right)=0.98$, $\mathrm{L}_{S \mathrm{~S}}$ is the sure save length which means $\mathrm{d}\left(\mathrm{L}_{\mathrm{SS}}\right)=0.02$ and $\mathrm{zss}$ is a constant equal to 1.45222 .

For defining the damage extent range, it is a common approach in naval ship design to consider 2 or 3 damaged compartments around the detonation compartment especially in case of absence of blast resistant bulkheads (Erkel and Galle, 2003). More detailed estimates may result from a careful risk assessment based on live firing tests analysis, the analysis of data from actual engagements, empirical formulas linking the damage range with the type and weight of the warhead or from the use of damage lengths/extents defined in current deterministic damage stability regulations for naval ships. In the latter case, which is the one proposed by Boulougouris and Papanikolaou (2004), a first approximation of the Lss can be taken according to naval codes DefStan 02-900 and DDS-079 and it would be 0.15L (see Table 1). The author's state that the $\mathrm{L}_{\mathrm{SK}}$ has can be assumed equal to $0.02 \mathrm{~L}$.

By combining the impact point and damage length density functions the probability of damage lying between the boundaries $\mathrm{x} 1$ and $\mathrm{x} 2$ or a naval ships compartments is;

$$
p_{i}=\int_{0}^{y} \operatorname{Dam}(y) \int_{x_{1}+\frac{y}{2}}^{x_{2}-\frac{y}{2}} \operatorname{imp}(x) d x d y
$$

The equations resulting from substituting $\operatorname{Dam}(\mathrm{y})$ and $\operatorname{Imp}(\mathrm{x})$ into equation (6) were presented in Boulougouris and Papanikolaou (2004).

As with a collision the extent of damage from a threat weapon will vary in magnitude transversely and vertically. The transverse damage penetration especially from ASM threats can vary extensively and in cases can extend across the full hull. Weapons fitted with timedelay fuses will penetrate the hull to an optimum position before detonating. However, the damage penetration distribution is not an 'issue' for surface combatants as longitudinal subdivision which would lead to asymmetrical flooding is avoided by design.

For the assessment carried out a log-normal distribution with maximum probability at the centreline was utilised for the damage penetration distribution in order to calculate reduction factors for various damage cases. The vertical extent of damage may also vary depending on the weapon's characteristics. In a surface combatant such as a frigate or a destroyer there are 3 vertical watertight boundaries, namely the tanktop, the damage control deck and the main deck. Excessive vertical watertight boundaries are avoided by design as high flooding can lead to poor stability thus it can be favourable to allow lower decks to flood. In the case of an air delivered weapon (e.g. Anti-Ship Cruise Missile) it will generally detonate close to the waterline causing greater damage above the waterline and the tank top will most likely remain intact. Still, in the case of an underwater weapon (e.g. contact mine or torpedo) which detonates close to the keel, the damage control deck will likely remain intact. The problem with an underwater explosion is that modern under-keel torpedoes are capable of causing extensive damage to the keel girder of even a cruiser sized ship, often this is sufficient to cause breaking and sinking of the ship. Such cases are not covered in the proposed 
methodology as the maintenance of structural integrity is a perquisite for the assessment of the ships damage stability.

For a hit by an air-delivered weapon, a linear distribution for the probability density function of the vertical extent of damage can be used. Its maximum is at the main deck and the minimum at the keel, the opposite is valid for an underwater weapon (see figure 1) (Boulougouris and Papanikolaou, 2013). By considering the vertical extent of damage the effect of the position of vertical watertight boundaries on the overall survivability of the vessel can be observed. In order to take into account both threats, a weighting factor can be applied according to an operational analysis of potential threats.

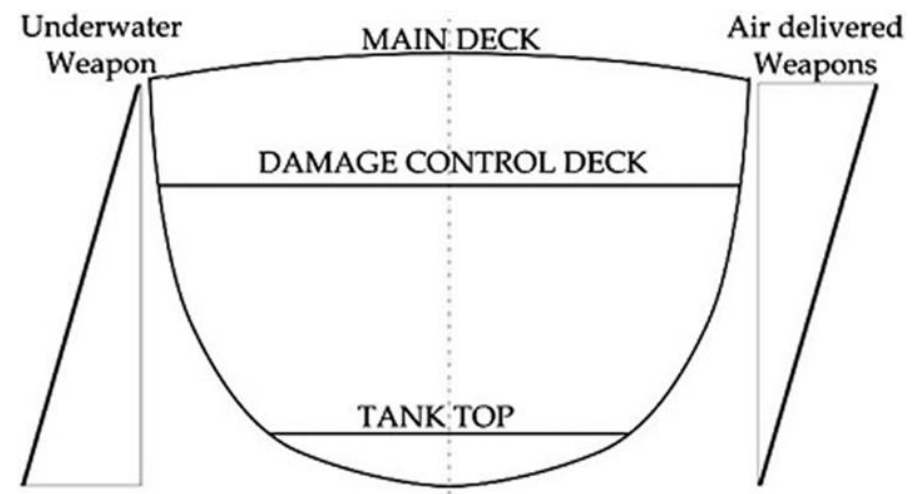

Figure 1 Naval Ship Vertical Watertight Boundaries

\subsection{Survival Index $S_{i}$}

The probability of survival of an intact frigate in waves is related by Mc Taggart and de Kat to the probability of capsize, which in turn is related to the probability of exceeding a critical roll angle $\mathrm{P}\left(\varphi>\varphi_{\text {critical }}\right)$ (Mc Taggart, 2000). In the case of a damaged ship the probability of survival has to take into consideration the probability of sinking without a capsize. For the determination of these probabilities, the Naval Stability Standards Working Group (NSSWG) is using FREDYN (De Kat, 1994), a time domain simulation tool (Perrault, 2010).

Another approach to assess the probability of survival after damage is a probabilistic quasistatic approach adjusted for the currently valid, semi-empirical deterministic criteria for naval ships (Boulougouris and Papanikolaou, 2013). The approach considers the probability of survival after damage and is based on quasi-static survival criteria such as those used by the Royal Navy and US Navy. The criteria were developed from real life damage incidences of WWII and although the current criteria have been under criticism as being outdated they have proved reliable over the years and thus there have been no significant changes. One of the main criticisms of the current criteria is the fundamental assumption that the sea conditions at the time of damage are "moderate". This constraint was lifted in the proposed methodology with the requirement for a specific survival sea state in case of damage.

This allows the correction of these requirements by consideration of the probability of exceedance of the wave height considered as basis for the current deterministic RN and USN criteria, namely a significant wave height $\mathrm{H}_{\mathrm{S}}$ of merely $8 \mathrm{ft}$. The wave height is used in the criteria in order to define $\varphi_{\text {roll, }}$ the roll amplitude due to wave action. It was also the 
underlying assumption behind the guidelines for establishing the watertight features/closures to prevent progressive flooding. Thus, any attempt to change the wave amplitude must take into account changes in both $\varphi_{\text {roll }}$ as well as the margin line or equivalent.

As can be seen from Table. 2, the criteria allow the sea state at the time of damage to be explicitly accounted for in the probabilistic assessment. The sea state is herein accounted for by $\mathrm{Hs}(0.99)$, which represents the wave height with a $99 \%$ probability of non-exceedance for the chosen operational area. This wave height is used for the definition of minimum freeboard and represents the most extreme conditions, which the damage ship could be exposed to in that operational area. In addition to the $99^{\text {th }}$ percentile $\mathrm{H}_{\mathrm{s}}$. the probability that the classical navy criterion of $8 \mathrm{ft}$ wave height will not be exceeded, $\mathrm{P}$ ( $\mathrm{H}_{\mathrm{S}} \leq 8 \mathrm{ft}$ ), in the operational area is also specified in the criteria. This parameter defines the probability of survival when the ship meets the current U.S.N or RN criteria.

The wind speed is another important parameter which needs to be considered, however given the small probability of exceeding the values given by RN and U.S Navy standards, the values were left unchanged (approximately 33 knots for a 3500t frigate). Table 2 shows the criteria which were applied in the frame of a probabilistic approach to assess the survivability of a generic frigate.

For intermediate stages, interpolant values can be used. Figure 2 shows the meaning of various notions of the righting arm curve.

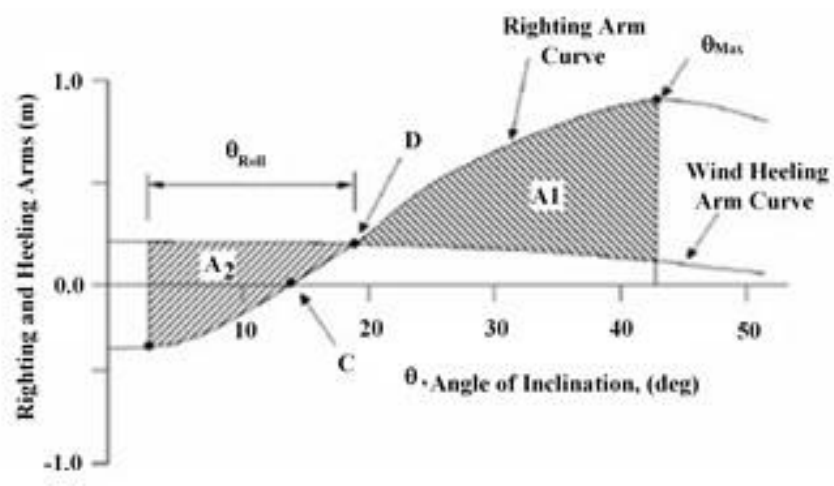

Figure 2 Damaged ship GZ criteria

Table 2 Probabilistic damage stability criteria for naval combatants

\begin{tabular}{ccc}
\hline $\mathrm{s}_{\mathrm{i}}=1$ & $\begin{array}{c}\Theta_{\text {roll }}=25 \mathrm{deg} \\
\mathrm{A}_{1} \geq 1.4 \mathrm{~A}_{2}\end{array}$ & $\begin{array}{c}\text { Wind Speed = According to Defstan 02-900 } \\
\text { Min Freeboard } \geq 3 \mathrm{in}+0.5\left(\mathrm{H}_{\mathrm{s}}(0.99)-8 \mathrm{ft}\right)\end{array}$ \\
\hline $\mathrm{s}_{\mathrm{i}}=\mathrm{P}\left(\mathrm{H}_{\mathrm{s}} \leq 8 \mathrm{ft}\right)$ & \multicolumn{2}{c}{ Ship meets Defstan 02-900 damage Stability Criteria } \\
\hline \multirow{3}{*}{$\mathrm{s}_{\mathrm{i}}=0$} & $\Theta_{\text {roll }}=15 \mathrm{deg}$ & Wind Speed = According to Defstan 02-900 \\
& $\mathrm{A}_{1} \leq 1.05 \mathrm{~A}_{2}$ & Longitudinal trim < required to cause downflooding \\
\hline
\end{tabular}


Implementing the above criteria for ships operating in North Atlantic $\mathrm{P}\left(\mathrm{H}_{\mathrm{S}} \leq 8 \mathrm{ft}\right)$ would be 0.56 and for East Mediterranean Sea 0.90 (Athanassoulis and Skarsoulis, 1992). For the North Pacific P $\left(\mathrm{H}_{\mathrm{S}} \leq 8 \mathrm{ft}\right.$ ) would be 0.42 (Lee, 1995) and for the South China Sea 0.71 (Haveman et al., 2006).

Therefore, a combatant, meeting the U.S. Navy or RN criteria for warships, should have according to the proposed criteria a 56\% probability of survival in the North Atlantic for a damage length not exceeding the current regulations (Ochi, 1978). This probability will increase to $90 \%$ probability of survival in the Mediterranean Sea and to $71 \%$ in the South China Sea. On the other hand, in the case of the North Pacific the probability of survival will decrease to $42 \%$. Obviously a similar methodology can be introduced for auxiliary naval vessels. The minimum required values for compliance could be estimated after application of the above procedure to sample/existing ships.

\section{CASE STUDY}

Both the current deterministic approach and newly presented probabilistic approach were applied to a generic frigate model which was defined in the Maxsurf package (Bentley Systems, 2013). The stability of the vessel was assessed using Maxsurf stability advanced. The ships main particulars are given in Table 3 and the 3D hull model is shown in Figure 3.

Table 3 Main Particulars

\begin{tabular}{cc}
\hline \multicolumn{2}{c}{ Main Particulars } \\
\hline Loa (m) & 148.1 \\
Lwl (m) & 137 \\
Twl (m) & 4.31 \\
Depth (m) & 9.3 \\
Displacement (tons) & 4528 \\
\hline
\end{tabular}

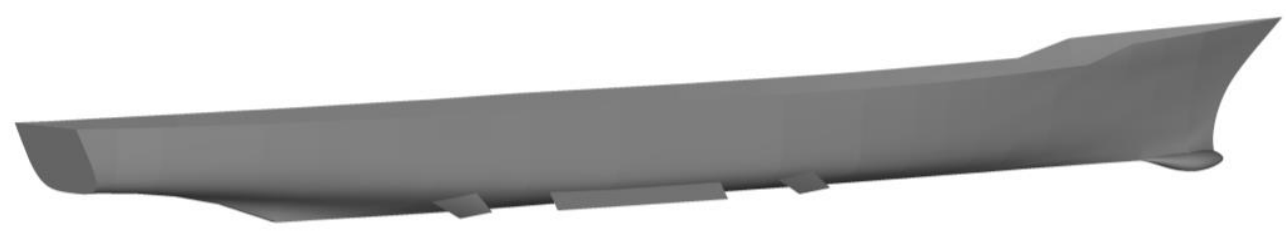

Figure 3 Frigate 3D hull model

The arrangement is typical for a frigate of this size with a centreline passageway providing an un-flooded route across the full length of the damage control deck. The ship has two main engine rooms, one for two cruise gas turbines and the other for two boost gas turbines. Furthermore, there are two auxiliary machinery rooms forward and aft of the GT rooms. The internal layout of the frigate consisted of 13 watertight transverse bulkheads which subdivide the hull into 14 main compartments. Three decks form the horizontal watertight boundaries, namely the main deck ( $1^{\text {st }}$ deck $)$, damage control deck ( $2^{\text {nd }}$ deck $)$ and the tank top $\left(4^{\text {th }}\right.$ deck). 
The ship has a $4528 \mathrm{t}$ displacement at full load condition without a growth margin and has a VCG of $5.53 \mathrm{~m}$ resulting in a $\mathrm{GM}_{\text {corr }}$ of $1.097 \mathrm{~m}$. At this condition the ship fulfils the intact stability criteria outlined in DefStan 02-900.

Initially the deterministic assessment was carried out in which all damage cases had to meet the criteria outlined in DefStan 02-900. The specified survivable damage length specified (15\%Lwl) resulted in a damaged length of $20.55 \mathrm{~m}$, thus the minimum length of $21 \mathrm{~m}$ was used to define the damage cases. This resulted in mainly 3 compartment damage cases. Several different transverse extents were taken for each damage case including B/5, B/2 and penetration across the full beam to ensure to worst possible cases were considered. As the frigate model was designed to this standard all damage cases fulfilled the criteria.

For the quasi-static probabilistic approach damage cases up to 6 adjacent zones were initially considered, however the probability of occurrence of both 5 and 6 compartment damage extents was found to be insignificant. A total of 226 damage cases extending up to 4 adjacent damage zone were defined in Maxsurf stability. The formulas for the calculation of the probability of damage occurring, $p_{i}$, from equation (6), were applied to the basis ship and results for single compartment damage zones are given in Table 4.

Table $4 \mathrm{p}_{\mathrm{i}}$ for frigate 1 compartment damage cases

\begin{tabular}{cccccccc}
\hline Room & $\mathrm{NZ}$ & $\mathrm{x}_{1}$ & $\mathrm{x}_{2}$ & $\mathrm{x}_{1} \mathrm{u}$ & $\mathrm{x} 2 \mathrm{u}$ & $\mathrm{y}$ & $\mathrm{Pi}$ \\
\hline 1 & 1 & 0 & 13 & 0.000 & 0.095 & 0.095 & 0.007 \\
2 & 1 & 13.0 & 23.5 & 0.095 & 0.172 & 0.076 & 0.011 \\
3 & 1 & 23.5 & 29.3 & 0.172 & 0.214 & 0.042 & 0.002 \\
4 & 1 & 29.3 & 41.1 & 0.214 & 0.301 & 0.087 & 0.030 \\
5 & 1 & 41.1 & 51.6 & 0.301 & 0.377 & 0.076 & 0.029 \\
6 & 1 & 51.6 & 62.0 & 0.377 & 0.453 & 0.076 & 0.036 \\
7 & 1 & 62.0 & 72.5 & 0.453 & 0.529 & 0.076 & 0.042 \\
8 & 1 & 72.5 & 79.5 & 0.529 & 0.581 & 0.052 & 0.011 \\
9 & 1 & 79.5 & 89.1 & 0.581 & 0.650 & 0.070 & 0.026 \\
10 & 1 & 89.1 & 102.3 & 0.650 & 0.747 & 0.097 & 0.046 \\
11 & 1 & 102.3 & 109 & 0.747 & 0.796 & 0.048 & 0.004 \\
12 & 1 & 109.0 & 117.6 & 0.796 & 0.859 & 0.063 & 0.008 \\
13 & 1 & 117.6 & 128 & 0.859 & 0.935 & 0.076 & 0.008 \\
14 & 1 & 128 & 137 & 0.935 & 1.000 & 0.065 & 0.001 \\
\hline
\end{tabular}

For the given subdivision arrangement, damage length and longitudinal distribution, 1 compartment damage cases contribute approximately 0.27 whereas 2,3 and 4 compartment cases contribute $0.6,0.11$ and 0.01 respectively. 


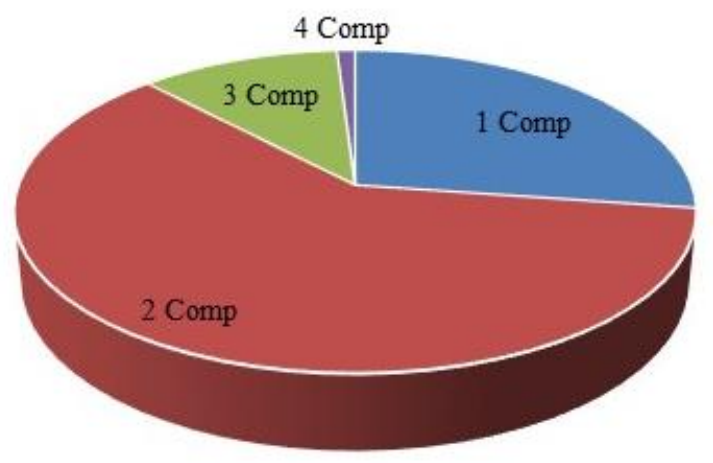

Figure 4 Contribution of various damage cases to attained index

Two different operational areas were considered in order to determine the influence of sea state on survivability, considering the criteria given in Table 2. For the North Atlantic Scenario, we assume P $(\mathrm{Hs} \leq 8 \mathrm{ft})=0.56$ and $\mathrm{Hs}(0.99)=10 \mathrm{~m}$, for the North Pacific P $(\mathrm{Hs} \leq 8 \mathrm{ft})$ $=0.42$ and Hs $(0.99)=11.2 \mathrm{~m}$.

For the frigate under consideration at full load condition the attained index was found to be $A=0.98$ for the North Atlantic and A=0.95 for the North Pacific Scenario. The survivability of the mobility function was calculated using equation (3) where $\mathrm{j}$ are all the main engine room compartments; in this case 5,6 and 7. This resulted in a mobility survivability index of 0.87 .

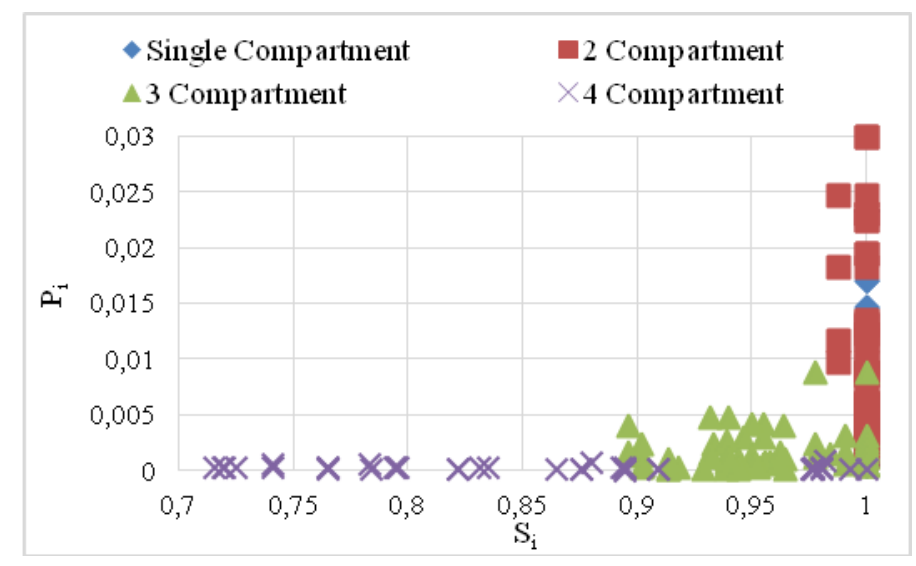

Figure 5 North Pacific $p_{i}$ against $s_{i}$

Figure 5 shows the damage cases which are most likely to occur and their corresponding probability of survival for the specified location conditions. The results illustrate that the vessel has a low risk of being lost due to damage up to two compartments. Due to the length of damage utilised, up to two adjacent compartments contributes approximately 0.87 to the attained index. The risk increases significantly for four or more adjacent compartments; however, the probability of occurrence of this extent of damage is too low to affect the overall attained index.

The conducted study suggests that the probabilistic approach can be readily used minimising the vulnerability of the vessel in the early stages of the design. The results from this approach can be easily visualised making the comparison of many different designs more concise for the designer. As the result of a deterministic assessment is simply a 'pass or fail' for each of the damage cases, it is actually difficult to quantify the effect of any major design change on 
the overall survivability of the vessel. Furthermore, the use of the attained survivability index in the probabilistic approach enables the designer to adopt a holistic approach to naval ship survivability and allows him to easily monitor the influence of his decisions on the survivability.

Whatever deterministic damage length is defined, it directly influences the position of transverse watertight bulkheads; namely, the specified deterministic length of damage implies that the length of either two or three compartments should be kept slightly larger than the damage length. This results in larger ships being designed with longer compartments to limit the extent of flooding in fewer compartment cases. Therefore, the deterministic subdivision methodology simply follows the concept of compliance with a set of deterministic criteria, as opposed to an optimisation for maximum survivability for a range of damage lengths of varying probability of occurrence. The use of the probabilistic approach in a formal, multiobjective optimisation procedure allows the designer to rationally achieve the optimum level of survivability, while keeping ship's weight and shaft length to a minimum (Boulougouris and Papanikolaou, 2013).

By relaxing the assumption for a moderate sea state $(\mathrm{Hs}=2.4 \mathrm{~m}$ or $8 \mathrm{ft})$ at the time of damage, it gives a more demanding and realistic set of criteria, which can ultimately result in a higher level of survivability. The currently used significant wave height in the deterministic approach has a 58\% chance of exceedance in the North Pacific and a $44 \%$ chance of exceedance in the North Atlantic. Thus, it does not properly reflect the harsh environments, which modern surface combatants are expected to operate in. Through the application of the probabilistic approach, the survival sea state can be explicitly defined in the criteria (Table. 2). This allows the ship's survivability to be assessed on the basis of mission area performance requirements. The results illustrate the influence of the operational area on survivability, with the probability of survival decreasing by 3\% when changing from the North Atlantic to the North Pacific.

\subsection{Damage Length}

The current IMO regulations for dry cargo and passenger ships (IMO MSC.216 (82)) consider collision damage lengths of up to $24 \% \mathrm{~L}_{\mathrm{bp}}$, thus any length of damage over $24 \% \mathrm{~L}_{\mathrm{bp}}$ is considered as statistically insignificant. This means that collision damage extents of less than $24 \% \mathrm{~L}_{\mathrm{bp}}$ (but still greater than $15 \%$ weapon damage length) are statistically significant.

In order to develop a refined set of probabilistic criteria for naval ships extensive calculations must be carried out on a sample of ships, which comply with the current damage stability regulations. A study was carried out in order to explore the effects of the damage length in which the ship is expected to survive on the overall survivability. The aim was to provide insight regarding the extent of damage modern naval ships are capable of surviving. This can therefore lead to a more rational approach of basing the damage extent on an assessment of threat while still having a set of criteria which can be reasonably met resulting in a higher level of survivability.

Initially the maximum length of damage was increased from $15 \% \mathrm{~L}_{\mathrm{wl}}$ (or $21 \mathrm{~m}$ ) to $20 \% \mathrm{~L}_{\mathrm{bp}}$ for the deterministic assessment. This led to a damage length of $27 \mathrm{~m}$ resulting in a majority of four compartment damage cases. The new length of damage fulfilled the deterministic criteria 
for all cases; however, the criteria were met with a much lower margin for the 4 compartment cases. A single 5 compartment case at the bow of the vessel was also assessed in which it passed the reserve buoyancy criteria by $0.17 \mathrm{~m}$.

Similarly, for the quasi-static probabilistic assessment the maximum length of damage in the distribution was increased from $15 \%$ to $24 \% \mathrm{~L}_{\mathrm{wl}}$. The value of $\mathrm{L}_{\mathrm{ss}}$ (equation 5) was set to $20 \% \mathrm{~L}_{\mathrm{bp}}$ which altered the damage length distribution. For the new damage length, 1 compartment cases now contribute 0.22 and 2, 3 and 4 compartment damage cases contribute $0.57,0.17$ and 0.03 respectively. For a 15\% damage length, 1 and 2 compartment cases contributed 0.87 to the attained index; however, that decreased to 0.79 for a $0.2 \mathrm{~L}$ damage. An attained index of $A=0.96$ was obtained for the North Atlantic scenario and $A=0.93$ for the North Pacific scenario. Finally, the damage length was increased to 0.24L. As collision damage extents over $0.24 \mathrm{~L}$ are considered to be statistically insignificant this was taken as the maximum value for the study. At approximately $1 / 4$ of the ships lengths this resulted in a large number of 5 compartment damage scenarios for the deterministic assessment. At this point the basis frigate failed the assessment in several cases due to both insufficient transverse stability and reserve buoyancy.

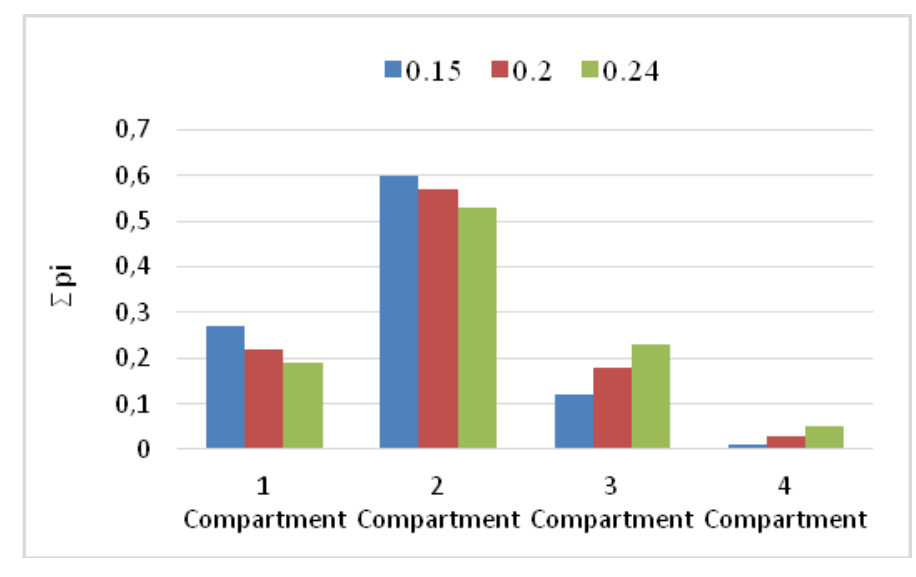

Figure 6 Contributions to attained index

For the probabilistic assessment the $0.24 \mathrm{~L}$ damage length led to an attained index of $A=0.94$ for the North Atlantic and A=0.90 for the North Pacific Scenario. The 4 and 5 compartment cases now contribute a maximum of 0.05 to the attained index as opposed to approximately 0.01 for the $0.15 \mathrm{~L}$ case. Figure 6 and 7 show the difference in contribution to the attained index for various damage cases and the effect on the attained index for each of the maximum damage lengths investigated. 


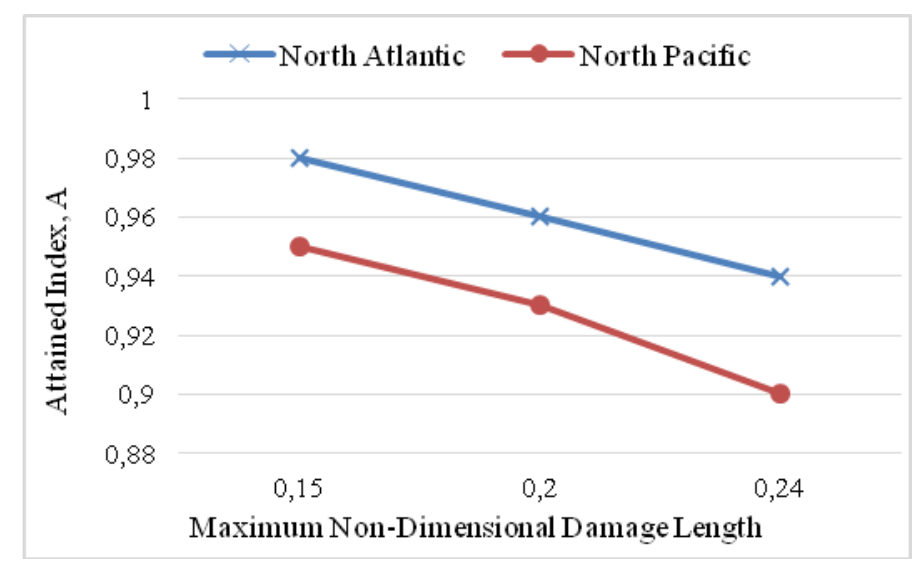

Figure 7 Survivability against max damage length

Figure 8 illustrates the different contributions to the attained index for the frigate under consideration in the outlined probabilistic approach and also when considering IMO MSC.216 (82); both assessments are for a damage length of 0.24L. As a damage from a threat weapon will result in greater damage extent than from collision, there is a peak at two compartment damage as opposed to one compartment damage in the case of the linear distribution of SOLAS.

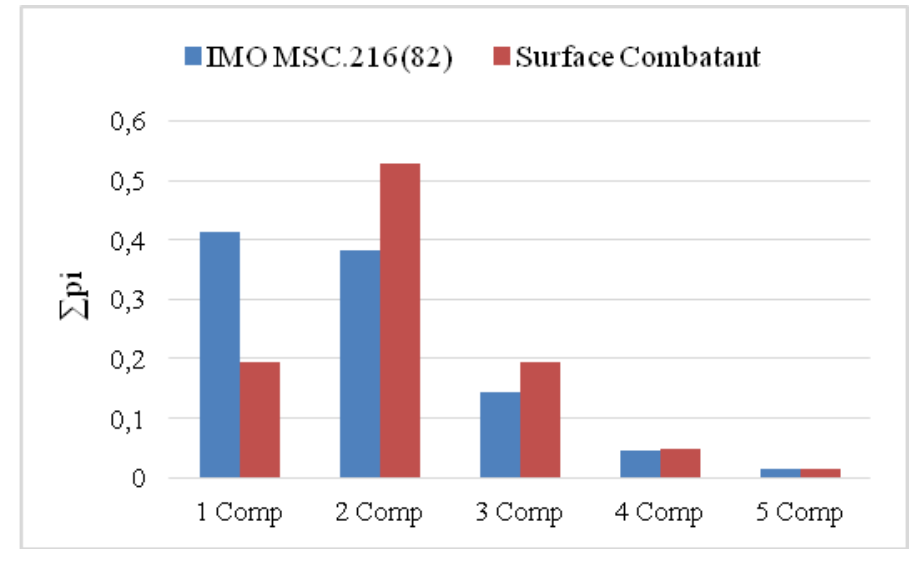

Figure 8 Comparison of damage length distributions

Although SOLAS considers damage lengths up to $0.24 \mathrm{~L}_{\mathrm{bp}}$, the use of the linear damage length distribution results in a more conservative estimate of the level of survivability. The linear distribution from SOLAS 2009 was applied and an attained index of $A=0.97$ was obtained for the North Atlantic and A=0.94 for the North Pacific. Using the log-normal distribution with the same maximum length of damage $(0.24 \mathrm{~L})$ the values obtained where $\mathrm{A}=0.94$ for the North Atlantic and $\mathrm{A}=0.90$ for the North Pacific.

It is observed that the log-normal distribution is more practical for naval ships as it can accurately represent the extent of damage associated with weapon effects. The use of the lognormal distribution will increase the likelihood of occurrence of damage cases involving multiple adjacent zones, therefore resulting in a more accurate estimate of survivability. 


\section{CONCLUSION}

The use of a probabilistic approach to assess the damage stability of a naval combatant can lead to a higher level of survivability. The use of the probabilistic assessment through the attained subdivision index allows a holistic approach to be taken to surface ship survivability. This allows ship's subdivision to be optimised for minimum risk (or maximum Attained Index) making survivability a distinct feature of the naval ship design and no longer a requirement. In addition, the use of more realistic operating conditions such as sea state at the time of damage will give the designer a better understanding of the damaged ship's performance and limitations.

The conducted study on the damage length margin for a naval ship shows that the length can be readily increased to more accurately represent damages reflecting possible weapon threats and without compromising the position of bulkheads. It illustrates that current naval vessels are capable of surviving greater damage lengths than previously specified. Thus, altering the damage length distribution for naval ships appears to be fully justified, whereas the impact on design is not anticipated to be drastic. In any case, the length of damage can be more rationally refined, namely based on current weapon threats which a combatant may face in its life cycle, resulting in a more realistic representation of the ship's survivability.

\section{REFERENCES}

Athanassoulis, G., Skarsoulis, M., 1992. Wind and Wave Atlas of the North-Eastern Mediterranean Sea. NTUA-SMHL Publ.

Ball, R.E., Calvano, C.N., 1994. Establishing the Fundamentals of a Surface Ship Survivability Design Discipline. Nav. Eng. J. 106, 71-74.

Bentley Systems, 2013. Maxsurf Marine Vessel Analysis and Design Software [WWW

Document]. URL http://www.bentley.com/en-

US/Products/Maxsurf/Marine+Vessel+Analysis+and+Design.htm

Boulougouris, E., Papanikolaou, A., 2013. Risk-based design of naval combatants. Ocean Eng. 65, 49-61.

Boulougouris, E.K., Papanikolaou, A.D., 2004. Optimisation of the Survivability of Naval Ships by Genetic Algorithms. Compit 04, 175-189.

De Kat, J. O., Brouwer, R., Mc Taggart, K.A., and Thomas, W.L., 1994. Intact ship survivability in extreme waves: New Criteria From a research and naval perspective. $5^{\text {th }}$ International Conference on Stability of Ships and Ocean Vehicles (STAB '94), Melbourne, Florida, USA, 7-11 November 1994 (Volume 1), 105-130.

Erkel, A.G., Galle, L.F., 2003. TNO-PML Developments of Blast Resistantdoors and walls. 8th International Marine Design Conference (IMDC2003), Athens, Greece, 5-8 May 2003 (Volume 2), 753-764.

Harmsen, E., Krikke, M., 2000. A probabilistic damage stablity calculation method for naval vessels, in: International Conference on Stability of Ships and Ocean Vehicles (STAB'00), 330-350. 
Haveman, C., Parliament, J., Sokol, J., Swenson, J., Wagner, T., 2006. Design of a Floating, Production, Storage, and Offloading Vessel for Operation in the South China Sea-OCEN 407 -Design of Ocean Engineering Facilities, Texas A\&M University.

Jasionowski, A., Vassalos, D., 2011. Conceptualising Risk, Neves, M., Belenky, V., de Kat, J., Spyrou, K., Umeda, N. (Eds.), Contemporary Ideas on Ship Stability in Waves, 4764.

Lee, W.T., 1995. Global Wave Statistics for Structural Design Assessments. Naval Surface Warfare Center, Carderock Division, Hydromechanics Directorate, R\&D report NSWCCD-HD-1048-01, October 1995.

Mc Taggart, K.A, De Kat, J. O., 2000. Capsize Risk of Intact Frigates in Irregular Seas, SNAME Transactions 108, 147-177.

Ochi, M.K., 1978. Wave Statistics for the Design of Ships and Offshore Structures. Publ. Soc. Nav. Archit. Mar. Eng. 86, 1-23.

Perrault, D., Hughes, T., Marshall S., 2010. Developing a Shared Vision for Naval Stability Assessment. Proc. ISSW2010, 115-120.

Przemieniecki, J.S., 1994. Mathematical methods in defense analyses, AIAA education series, ISBN 1563470926.

Said, M.O., 1995. Theory and Practice of Total Ship Survivability for Ship Design. Nav. Eng. J. 107, 191-203.

Sarchin, T., Goldberg, L., 1960. Stability and Buoyancy criteria for U.S. naval surface ships. SNAME Trans. 70, 418-458.

Surko, S.W., 1994. An Assessment of Current Warship Damaged Stability Criteria. Nav. Eng. J. 106, 120-131.

UK MOD, 2013. Defence Standard 02-900 Part 1.

Wendel, K., 1960. Die Wahrscheinlichkeit des Überstehens von Verletzungen. J. Schiffstechnik-Ship Tech. Res.7, 47-61. 


\section{FIGURE CAPTIONS}

Figure 1 - Naval Ship Vertical Watertight Boundaries

Figure 2 - Damaged ship GZ criteria

Figure 3 - Basis frigate 3D hull model

Figure 4 - Contribution of various damage cases to attained index

Figure 5 - North Pacific $p_{i}$ against $s_{i}$

Figure 6 - Contributions to attained index

Figure 7 - Survivability against max damage length

Figure 8 - Comparison of damage length distributions 